\title{
Determination of the Content of Impurity Elements in Aluminum Alloy by XRF Analysis
}

\author{
Jinge Zhou, Jie Shi, Bo Zhang, Shaoqin Li \\ School of Nuclear Technology \& Automation Engineering, Chengdu University of Technology, Chengdu, China \\ Email: zjg1809424@163.com
}

How to cite this paper: Zhou, J.G., Shi, J., Zhang, B. and Li, S.Q. (2021) Determination of the Content of Impurity Elements in Aluminum Alloy by XRF Analysis. Open Access Library Journal, 8: e7836.

https://doi.org/10.4236/oalib.1107836

Received: August 5, 2021

Accepted: August 27, 2021

Published: August 30, 2021

Copyright $\odot 2021$ by author(s) and Open Access Library Inc.

This work is licensed under the Creative Commons Attribution International License (CC BY 4.0).

http://creativecommons.org/licenses/by/4.0/

\begin{abstract}
Aluminum alloy is one of the most widely used metal materials in today's society. Measurement and analysis of its impurity elements can effectively improve the performance of aluminum alloy. Energy dispersive X-ray fluorescence spectrometry (EDXRF) was used to analyze the types and contents of impurity elements in aluminum alloys, and the best working conditions for the EDXRF analyzer to measure impurity elements in aluminum alloys were determined. The absorption and enhancement effect of $\mathrm{Al}, \mathrm{Zn}, \mathrm{Cu}$ on impurity elements in $\mathrm{Ti}, \mathrm{Cr}, \mathrm{Mn}, \mathrm{Fe}, \mathrm{Cu}, \mathrm{Zn}$ in aluminum alloy was discussed, and the empirical coefficient method was used to correct it. The analytical precision of EDXRF was evaluated. The data show that the average relative errors of the impurity elements in the aluminum alloy are Ti: $7.50 \%, \mathrm{Cr}: 2.48 \%, \mathrm{Mn}$ : $0.99 \%$, Fe: $3.49 \%, \mathrm{Cu}: 0.44 \%, \mathrm{Zn}: 0.14 \%$, respectively. It shows that the XRF measurement method is feasible and the accuracy meets the requirements of engineering design.
\end{abstract}

\section{Subject Areas}

Nuclear Technology and Application

\section{Keywords}

Aluminum Alloy, Impurity Elements, XRF Analysis,

Absorption-Enhancement Effect

\section{Introduction}

Aluminum alloy material, as one of the most important metal materials in today's society, has the advantages of low density, corrosion resistance, good elec- 
trical conductivity and decoration. They have important applications in the fields of machinery, electronics, aerospace and equipment manufacturing [1]. The performance of aluminum alloy is determined by the content of aluminum and its other main elements, but some impurity elements will inevitably be mixed during the manufacturing process. When the content of impurity elements exceeds a certain level, it will also affect the performance of aluminum alloy. Therefore, the content of impurity elements in aluminum alloy has become one of the key parameters for evaluating the performance of aluminum alloy.

For the qualitative and quantitative analysis of the content of aluminum alloys element, there are mainly chemical analysis methods and instrumental analysis methods. The instrumental analysis method is mainly electron-coupled plasma atomic emission spectrometry (ICP-AES) [2] [3], which can realize simultaneous analysis of multiple elements with low detection limits, but the instruments are expensive, maintenance costs are high, and analysis speed is slow; chemical analysis methods need to use chemical reagents, which will damage the sample to be tested during the analysis process; the analysis speed is slow, and some chemical reagents are toxic, which will harm the operators. Energy dispersive $\mathrm{X}$-ray fluorescence spectrometry has the advantages of good precision, multi-element online measurement, fast analysis speed, no sample making, and non-destructive analysis, which has a very broad application prospect in the analysis of alloy materials [4] [5] [6]. In recent years, many researchers have also carried out the measurement of the main elements of aluminum alloy by X-ray fluorescence spectrometry in order to measure the content of impurity elements in aluminum alloy.

\section{Basic Theory}

\subsection{Qualitative and Quantitative Analysis}

According to Moseley's law, when the primary X-ray irradiates the sample to be tested, the proportional relationship between the energy $E_{n}$ of characteristic $\mathrm{X}$-ray and the atomic number $Z$ of element that emits the characteristic X-ray is:

$$
E_{n}=-R h c(Z-\sigma)^{2}\left(\frac{1}{n_{f}^{2}}-\frac{1}{n_{i}^{2}}\right)
$$

where $R$ is the Rydberg constant, $1096.776 \mathrm{~m}^{-1}$; h is the Planck constant, $6.626 \times$ $10^{-34} \mathrm{~J} \cdot \mathrm{S} ; c$ is the speed of light, $3 \times 10^{8} \mathrm{~m} \cdot \mathrm{s}^{-1}$; $\mathrm{Z}$ is the atomic number of the excited element; $\sigma$ is the shielding coefficient; $n_{f}$ and $n_{i}$ are the number of electron shells.

Assuming that the elements in the sample to be tested are uniformly distributed, and the sample has an infinitely large smooth surface, the basic formula for the $\mathrm{X}$ fluorescence counting rate of the element to be tested can be expressed as:

$$
I_{k}=\frac{K I_{0}}{\mu_{0}+\mu_{k}} C
$$


where $I_{0}$ is the intensity of the primary X-ray; $\mu_{0}$ is the attenuation coefficient of the incident X-ray; $\mu_{k}$ is the attenuation coefficient of the characteristic X-ray; $C$ is the element content; when the measurement conditions and the measurement object remain unchanged, the $K$ value remains unchanged.

\subsection{Correction of Matrix Effect}

When the detection device is confirmed, the value of $K I_{0}$ of the specific element is determined in formula (2), but the value of $\mu_{0}+\mu_{K}$ will change due to the matrix effect of the sample. The matrix effect mainly includes absorption-enhancing effect, non-uniform effect, surface effect and chemical valence effect. The sample used in the experiment is a cylindrical solid alloy sample, and the surface is polished, so the main consideration is the influence of the absorption-enhancement effect caused by the different composition of the sample. In the measurement of impurity elements in aluminum alloys, the sample to be tested contains a variety of elements, which causes the absorption-enhancement effect to be particularly significant. Therefore, when calculating the content of impurity elements, it is necessary to correct the influence caused by it. After obtaining the count rate of aluminum alloy sample, through polynomial fitting of count rate and content, the correction equation of impurity element content and its count rate is obtained:

$$
W_{i}=A_{0}+B_{0} I_{0}+B_{1} I_{1}+\cdots+B_{n} I_{n}
$$

where $W_{i}$ is the content of the element to be measured; $A_{0}, B_{0}, B_{1} \ldots B_{n}$ are empirical coefficients, which are obtained by multiple linear regression; $I_{0}$ is the fluorescence intensity of the element to be measured; $I_{1} \ldots I_{n}$ are the characteristic X-rays intensity of the corresponding interfering element; $\mathrm{n}$ is the number of correction element.

\section{Experimental Conditions}

\subsection{Experimental Instrument}

The instrument used for the measurement is the desktop X-fluorescence analyzer Epsilon1 produced by Malvern Panalytical, Netherlands. The temperature and pressure sensors are set inside to compensate for changes in the atmosphere to ensure high quality and high sensitivity. The X-ray tube voltage can reach 50 $\mathrm{keV}$ with thin-window Ag anode, which is suitable for exciting heavy elements. It can realize the rapid online measurement of major, trace and trace elements from sodium to americium, and the detection limit LLD reaches 1 ppm-100\%.

\subsection{Determination of X-Ray Tube Working Conditions}

The count rate and peak-to-back ratio of the element to be measured are mainly used as the selection criteria for determining the best working conditions of the $\mathrm{X}$-ray tube, while considering the power of the $\mathrm{X}$-ray tube and the maximum allowable relative error of the measurement. In the experiment, the method of 
controlling variables is used to determine the parameters of filter, optimal tube voltage, and optimal tube current in sequence. The samples used and the measurement position remains unchanged. The final selected parameters are shown in Table 1. Under the premise of not affecting the experimental accuracy, try to increase the value of the count rate and reduce the relative error. The relative errors of the six elements to be measured are: Ti, Cr: $1.27 \%, \mathrm{Mn}: 1.89 \%$, Fe: $0.33 \%, \mathrm{Cu}: 1.58, \mathrm{Zn}: 2.12 \%$.

\section{Discussion of Experimental Results}

The measured samples are cylindrical solid aluminum alloy samples $(\Phi 4 \mathrm{~cm} \times$ $\mathrm{H} 3 \mathrm{~cm}$ ). After polishing, the surface is smooth and flat, which can overcome the surface effect, non-uniformity effect and chemical valence effect. In the X-ray fluorescence analysis of aluminum alloys, the method of multiple regression is mainly used to correct the absorption-enhancement effect of each element to be measured of the aluminum alloy.

The $\mathrm{K}_{\alpha}$ characteristic $\mathrm{X}$-ray energies of $\mathrm{Ti}, \mathrm{Cr}, \mathrm{Mn}, \mathrm{Fe}, \mathrm{Cu}$, and $\mathrm{Zn}$ are 4.51 $\mathrm{keV}, 5.41 \mathrm{keV}, 5.895 \mathrm{keV}, 6.40 \mathrm{keV}, 8.04 \mathrm{keV}, 8.63 \mathrm{keV}$, which are all larger than the $\mathrm{K}$ absorption limit of $\mathrm{Al}$ of $1.49 \mathrm{keV}$. For the quantitative analysis of impurity elements in aluminum alloy samples, correction is mainly made to the absorption effect of Al. Secondly, the characteristic X-ray energy of $\mathrm{Cu}$ is close to the $\mathrm{Ka}$ absorption limit of $\mathrm{Mn}$ and $\mathrm{Fe}$, which will produce a more obvious enhancement effect. Therefore, the correction of $\mathrm{Mn}$ and Fe needs to be added to the correction of the enhancement effect of $\mathrm{Cu}$. In the same way, the characteristic X-ray energy of $\mathrm{Zn}$ is close to the $\mathrm{K}_{\alpha}$ absorption limit of $\mathrm{Cu}$. When calculating the content of $\mathrm{Cu}$ and $\mathrm{Zn}$, the absorption-enhancement effect needs to be corrected for each other.

It can be seen from Table 2 that the average relative error of $\mathrm{Ti}$ element is $7.50 \%$, the average relative error of $\mathrm{Cr}$ element is $2.48 \%$; it can be seen from $\mathrm{Ta}$ ble 3 that the average relative error of Mn element is $0.99 \%$, and the average relative error of Fe element is $0.99 \%$. It can be seen from Table 4 that the average relative error of $\mathrm{Cu}$ element is $0.44 \%$, and the average relative error of $\mathrm{Zn}$ element is $0.14 \%$. In the pure aluminum sample, the impurity element content is low, and the relative error is several times or even dozens of times that of the 6-series samples.

Table 1. Optimal pipe pressure and pipe flow in different measurement intervals.

\begin{tabular}{cccc}
\hline Measuring range & Optimal tube voltage $(\mathrm{keV})$ & Optimal tube current $(\mu \mathrm{A})$ & Filter \\
\hline $\mathrm{Na}-\mathrm{Si}$ & 17 & 75 & - \\
$\mathrm{K}-\mathrm{V}$ & 20 & 182 & $\mathrm{Al} 50$ \\
$\mathrm{Cr}-\mathrm{Co}$ & 21 & 98 & $\mathrm{Al} 50$ \\
$\mathrm{Ni}-\mathrm{Mo}$ & 46 & 98 & $\mathrm{Al} 50$ \\
\hline
\end{tabular}


Table 2. Binary regression analysis results of $\mathrm{Ti}$ and $\mathrm{Cr}$.

\begin{tabular}{|c|c|c|c|c|c|c|c|c|}
\hline \multirow{2}{*}{$\begin{array}{c}\text { Sample serial } \\
\text { number }\end{array}$} & \multicolumn{4}{|c|}{$\mathrm{Ti}$} & \multicolumn{4}{|c|}{$\mathrm{Cr}$} \\
\hline & $\begin{array}{c}\text { Theoretical } \\
\text { value (\%) }\end{array}$ & $\begin{array}{c}\text { Fitted } \\
\text { value (\%) }\end{array}$ & $\begin{array}{l}\text { Absolute } \\
\text { error (\%) }\end{array}$ & $\begin{array}{l}\text { Relative } \\
\text { error (\%) }\end{array}$ & $\begin{array}{l}\text { Theoretical } \\
\text { value (\%) }\end{array}$ & $\begin{array}{c}\text { Fitted } \\
\text { value (\%) }\end{array}$ & $\begin{array}{l}\text { Absolute } \\
\text { error (\%) }\end{array}$ & $\begin{array}{c}\text { Relative } \\
\text { error (\%) }\end{array}$ \\
\hline 1 & 0.017 & 0.01764 & 0.0006 & 3.75 & - & - & - & - \\
\hline 2 & 0.018 & 0.01941 & 0.0014 & 7.85 & - & - & - & - \\
\hline 3 & 0.015 & 0.01393 & -0.0011 & -7.13 & - & - & - & - \\
\hline 4 & 0.040 & 0.03954 & -0.0005 & -1.15 & 0.217 & 0.2230 & 0.0060 & 2.74 \\
\hline 5 & 0.048 & 0.03995 & -0.0081 & -16.78 & 0.171 & 0.1626 & -0.0084 & -4.93 \\
\hline 6 & 0.066 & 0.06958 & 0.0036 & 5.43 & 0.198 & 0.1981 & 0.0001 & 0.05 \\
\hline average & 0.034 & 0.03334 & 0.00255 & 7.50 & 0.195 & 0.1946 & 0.0048 & 2.48 \\
\hline
\end{tabular}

Table 3. Ternary regression analysis results of $\mathrm{Mn}$ and Fe.

\begin{tabular}{|c|c|c|c|c|c|c|c|c|}
\hline \multirow{2}{*}{$\begin{array}{c}\text { Sample serial } \\
\text { number }\end{array}$} & \multicolumn{4}{|c|}{$\mathrm{Mn}$} & \multicolumn{4}{|c|}{$\mathrm{Fe}$} \\
\hline & $\begin{array}{l}\text { Theoretical } \\
\text { value (\%) }\end{array}$ & $\begin{array}{c}\text { Fitted } \\
\text { value (\%) }\end{array}$ & $\begin{array}{l}\text { Absolute } \\
\text { error (\%) }\end{array}$ & $\begin{array}{c}\text { Relative } \\
\text { error (\%) }\end{array}$ & $\begin{array}{l}\text { Theoretical } \\
\text { value (\%) }\end{array}$ & $\begin{array}{c}\text { Fitted } \\
\text { value (\%) }\end{array}$ & $\begin{array}{l}\text { Absolute } \\
\text { error (\%) }\end{array}$ & $\begin{array}{c}\text { Relative } \\
\text { error (\%) }\end{array}$ \\
\hline 1 & 0.598 & 0.5956 & -0.0024 & -0.41 & 0.175 & 0.1768 & 0.0018 & 1.00 \\
\hline 2 & 0.975 & 0.9719 & -0.0031 & -0.32 & 0.139 & 0.1449 & 0.0059 & 4.23 \\
\hline 3 & 0.973 & 0.9753 & 0.0023 & 0.23 & 0.14 & 0.1414 & 0.0014 & 1.00 \\
\hline 4 & 0.058 & 0.0594 & 0.0014 & 2.38 & 0.377 & 0.3997 & 0.0227 & 6.01 \\
\hline 5 & 0.098 & 0.0847 & -0.0133 & -13.53 & 0.512 & 0.4937 & -0.0183 & -3.58 \\
\hline 6 & 0.387 & 0.3950 & 0.0080 & 2.06 & 0.172 & 0.1693 & -0.0027 & -1.59 \\
\hline average & 0.515 & 0.5137 & 0.0051 & 0.99 & 0.253 & 0.2543 & 0.0088 & 3.49 \\
\hline
\end{tabular}

Table 4. Ternary regression analysis results of $\mathrm{Cu}$ and $\mathrm{Zn}$.

\begin{tabular}{|c|c|c|c|c|c|c|c|c|}
\hline \multirow{2}{*}{$\begin{array}{c}\text { Sample serial } \\
\text { number }\end{array}$} & \multicolumn{4}{|c|}{$\mathrm{Cu}$} & \multicolumn{4}{|c|}{$\mathrm{Zn}$} \\
\hline & $\begin{array}{l}\text { Theoretical } \\
\text { value (\%) }\end{array}$ & $\begin{array}{c}\text { Fitted } \\
\text { value (\%) }\end{array}$ & $\begin{array}{l}\text { Absolute } \\
\text { error (\%) }\end{array}$ & $\begin{array}{c}\text { Relative } \\
\text { error (\%) }\end{array}$ & $\begin{array}{l}\text { Theoretical } \\
\text { value (\%) }\end{array}$ & $\begin{array}{c}\text { Fitted } \\
\text { value (\%) }\end{array}$ & $\begin{array}{l}\text { Absolute } \\
\text { error (\%) }\end{array}$ & $\begin{array}{l}\text { Relative } \\
\text { error (\%) }\end{array}$ \\
\hline 1 & 4.371 & 4.3672 & -0.0038 & -0.09 & 0.039 & 0.0391 & 0.0001 & 0.26 \\
\hline 2 & 0.081 & 0.0812 & 0.0002 & 0.26 & 0.005 & 0.0059 & 0.0009 & 18.38 \\
\hline 3 & 0.081 & 0.0804 & -0.0006 & -0.75 & 0.004 & 0.0050 & 0.0010 & 25.05 \\
\hline 4 & 0.035 & 0.0471 & 0.0121 & 34.56 & 0.021 & 0.0236 & 0.0026 & 12.45 \\
\hline 5 & 0.26 & 0.2492 & -0.0108 & -4.15 & 0.1 & 0.0969 & -0.0031 & -3.08 \\
\hline 6 & 1.777 & 1.7755 & -0.0015 & -0.09 & 5.792 & 5.7926 & 0.0006 & 0.01 \\
\hline average & 1.101 & 1.1001 & 0.0048 & 0.44 & 0.994 & 0.9939 & 0.0014 & 0.14 \\
\hline
\end{tabular}

\section{Conclusion}

The content of impurity elements $\mathrm{Ti}, \mathrm{Cr}, \mathrm{Mn}, \mathrm{Fe}, \mathrm{Cu}, \mathrm{Zn}$ in 6 series of aluminum alloys was analyzed and studied by EDXRF method. The best working conditions for the analysis of different impurity elements in aluminum alloy by Mal- 
vern Panalytical desktop Epsilon1 X fluorescence analyzer system were determined, and the influence of matrix effect in the EDXRF method was corrected by the empirical coefficient method. After the content of the sample, the mathematical model and linear regression equation between the content and the counting rate in the aluminum alloy sample are established for different impurity elements. The binary regression method is used for $\mathrm{Ti}$ and $\mathrm{Cr}$, and the ternary regression method is used for $\mathrm{Mn}, \mathrm{Fe}, \mathrm{Cu}, \mathrm{Zn}$ for matrix correction. It has greatly improved the measurement accuracy of impurities in the 6 series aluminum alloys. The average relative errors are Ti: $7.50 \%, \mathrm{Cr}: 2.48 \%, \mathrm{Mn}: 0.99 \%$, Fe: $3.49 \%$, Cu: $0.44 \%$, and $\mathrm{Zn}: 0.14 \%$. The results show that the measurement error of the aluminum alloy impurity elements is small within the detection limit, and the XRF measurement method can meet the analysis requirements of aluminum alloy impurity elements in industrial production.

\section{Acknowledgements}

Thanks for my junior brothers and sisters, Jiang Yunrui and Shi Jie, who give a lot of help in the experiment. Thanks to our school for providing me with a place to experiment.

\section{Conflicts of Interest}

The authors declare no conflicts of interest.

\section{References}

[1] Santa Coloma, P., Izagirre, U., Belaustegi, Y., et al. (2015) Chromium-Free Conversion Coatings Based on Inorganic Salts $(\mathrm{Zr} / \mathrm{Ti} / \mathrm{Mn} / \mathrm{Mo})$ for Aluminum Alloys Used in Aircraft Applications. Applied Surface Science, 345, 24-35. https://doi.org/10.1016/j.apsusc.2015.02.179

[2] Vanhaecke, F., Riondato, J., Moens, L. and Dams, R. (1996) Non-Spectral Interferences Encountered with a Commercially Available High Resolution ICP-Mass Spectrometer. Fresenius' Journal of Analytical Chemistry, 355, 397-400. https://doi.org/10.1007/s0021663550397

[3] Szalóki, I., Patkó, J. and Papp, L. (1990) Determination of Cr and Mn in Aluminium Wires and Sheets by XRF, NAA and AAS. Journal of Radioanalytical and Nuclear Chemistry, 141, 279-287. https://doi.org/10.1007/BF02035795

[4] Bertin, E.P. (1975) Principles and Practice of X-Ray Spectrometric Analysis. Plenum Press, New York, London. https://doi.org/10.1007/978-1-4613-4416-2

[5] Mzyk, Z., Anyszkiewicz, J. and Matusiak, H. (2012) Analysis of Alloy Composition by X-Ray Fluorescence Spectrometry Using Liquid and Thin Layer Techniques with an Internal Standard. Spectrochimica Acta Part B, 69, 44-49. https://doi.org/10.1016/j.sab.2012.03.004

[6] Sarbajna, C., Durani, S., Nayak, S., et al. (2013) Determination of U, S, V, Cu, Zn, $\mathrm{Sr}$, Mo and Ce in Carbonate Rocks by Wave Length Dispersive X-Ray Fluorescence Spectrometry and Inductively Coupled Plasma Optical Emission Spectrometry. Atomic Spectroscopy, 34, 31-38. https://doi.org/10.46770/AS.2013.01.006 